\title{
Green Synthesis of Nano-silver Particles Using Plant Active Substance from Lemongrass Extract
}

\begin{abstract}
Qifeng Chen, Ting Mi, Guangxue Chen,* and Yiwei Li
Biosynthesis of nanoparticles by plant extracts is currently under exploitation. Plant extracts are very cost effective and eco-friendly and thus can be an economic and efficient alternative. This study investigates the mechanism of preparation of nano-silver using a plant active substance from lemongrass extract. The lemongrass ethanol extract was prepared using an ultrasonic cell crusher. Spherical silver nanoparticles were prepared with lemongrass extract and silver nitrate. The reaction mechanism of the preparation of nano-silver by plant extracts was analyzed by infrared and X-ray photoelectron spectrometer (XPS) measurements. The uniform and stable spherical silver nanoparticles with an average particle size of $22.99 \mathrm{~nm}$ were synthesized. Amide compounds in plant extracts may act as reductants and protective agents. The biomass of plants produces their nanomaterials through a process called biomineralisation. Thus, plant active substances can be used widely, and biological methods are completely feasible and worth studying for the chemical procedures, which are environmentally friendly and convenient.
\end{abstract}

Keywords: Lemongrass extract; Silver nanoparticles; X-ray photoelectron spectrometer

Contact information: State Key Lab of Pulp and Paper Engineering, National Experimental Teaching Demonstration Center for Light Industry and Food, South China University of Technology, Guangzhou, 510640,China; *Corresponding author: mitingcri@foxmail.com

\section{INTRODUCTION}

Nano-silver particles show many unique physical and chemical properties due to their surface effect, quantum size effect, and macroscopic quantum tunneling effect (Ball and Garwin 1992). In recent years, nano-silver particles have attracted much attention because of their excellent conductivity, oxidation resistance, and low temperature sintering performance (Wang et al. 2007; Park et al. 2008). They are widely used in thick film printed circuits, internal electrodes, and sensors in multi-layer ceramic capacitors (Lin and Wang 1996; Zhang et al. 1996). In addition, nano-silver particles are also used as antibacterial materials (Lee et al. 2003), biosensor materials (Shaik et al. 2017), and lowtemperature superconducting materials (Hirano et al. 2003). Therefore, it is of great significance to study the preparation and application of nano-silver particles.

Nano-silver particles can be prepared through chemical reduction (Chou and Ren 2000; Pastoriza-Santos and Liz-Marzán 2002; Sun and Xia 2002; Khanna et al. 2005b; Ryu et al. 2005), electrochemical method (Rodríguez-Sánchez et al. 2000; Yin et al. 2003), electron beam evaporation deposition method (Korchagina et al. 2005), photocatalytic reduction method (Khanna et al. 2005a), magnetron sputtering (Xionget al. 2000), electrochemistry (Zhou et al. 2006), supercritical fluids (Chang et al. 2003), $\gamma$-ray method (Biswal et al. 2009), green synthesis method (Naik et al. 2002), seed media (Tian et al. 2007), microemulsion (Xie et al. 2006; Zhang et al. 2006), and laser melting method (Tsuji et al. 2003). Each method has advantages and disadvantages. In these methods, green 
synthesis is not only a good way to produce favorable nanostructured materials, but also to reduce the production of harmful substances in human health and the natural environment (Chandran et al. 2006).

Silver nanoparticles can be synthesized using plant extracts. Geetha et al. (2012) prepared silver nanoparticles or $40 \mathrm{~nm}$ by heating a mixture of native Indian grasses and silver nitrate solution at $70{ }^{\circ} \mathrm{C}$. Silver nanoparticles with different particle sizes under different reaction conditions have been prepared by the reaction of chestnut leaves extract and silver nitrate (Dan 2009). Manish et al. (2009) synthesized 50 to $150 \mathrm{~nm}$ silver nanoparticles by a eucalyptus methanol solution and silver nitrate. Chandran et al. (2006) prepared triangular gold nanoparticles and spherical nanosized silver particles using aloe extract. Song and Kim (2009) prepared silver nanoparticles of about $32 \mathrm{~nm}$ using magnolia, Platanus, pine, and Ginkgo biloba leaves.

Lemongrass is widely produced in the southern China subtropical region. It has a high survival rate, low price, fresh lemon flavor, and antibacterial properties. Some researchers earlier had successfully prepared the nano-silver particles by using Cymbopogan citratus (lemongrass) (Shalaka et al. 2011), but they had used very different experimental conditions in their method. It has been shown that using starch as a protective agent can make the prepared nano-silver particle size smaller, more stable, and more uniform. Compared with previous reports, this method is time-saving and effective.

This paper focuses on using lemongrass active extract to prepare nano-silver particles (Ajayi and Afolayan 2017). The effects of the amount of active substance and the soluble starch were examined. The synthesized nanoparticles were measured by ultravioletvisible (UV-vis) spectroscopy, transmission electron microscopy, Malvern nano-size and potential analyzer, and X-ray photoelectron spectrometry.

\section{EXPERIMENTAL}

\section{Materials and Equipment}

Analytical grade sodium hydroxide $(\mathrm{NaOH})$ (Tianjin Futong Chemical Reagents Factory, Tianjin, China), analytical grade silver nitrate $\left(\mathrm{AgNO}_{3}\right)$ (Sinopharm Chemical Reagent Co., Ltd., Beijing, China), analytical grade ammonia water (Zhejiang Sanying Chemical Reagent Co., Ltd., Lanxi, China), analytical grade anhydrous ethanol (Sinopharm Chemical Reagent Co., Ltd., Beijing, China), and analytical grade soluble starch (Shanghai Aladdin Biochemical Technology Co., Ltd., Shanghai, China) were used. Lemongrass was procured from crop ground of Xishuangbanna in Yunnan province.

The following laboratory equipment was used for this study: FZ102-type plant crusher (Beijing Zhongxing Albert Instrument Co., Ltd., Beijing, China), AL204-type electronic balance (Mettler-Toledo International Trading (Shanghai) Co., Ltd., Shanghai, China), DELTA320-type pH meter (Mettler-Toledo), TG16-W-type centrifuge (Shanghai Huyueming Technology Instrument Co., Ltd., Shanghai, China), ZEN3690-type Malvern nano-size and potential analyzer (Malvern Instruments, Ltd., Malvern, UK), DHG-type hot air drying oven (Shanghai Yiheng Technology Instrument Co., Ltd., Shanghai, China), and XH100B-type microwave catalytic synthesis/extract instrument (Beijing Cheung Swan Technology Development Co., Ltd., Beijing, China). 


\section{Preparation of Lemongrass Extract}

Three grams of washed and dried lemongrass was crushed into a powder and mixed with $70 \mathrm{~mL} 70 \%$ ethanol water solvent. The mixture was sonicated at $40{ }^{\circ} \mathrm{C}$ for $20 \mathrm{~min}$, using a reaction power of $350 \mathrm{~W}$. Then it was subjected to suction filtration to obtain a crude extract, and condensed into a sticky state by rotary evaporator, and freeze-dried to prepare the lemongrass extract powder.

\section{Preparation of Silver Nanoparticles}

Lemongrass extract powder $(0.4 \mathrm{~g})$ was dissolved in $20 \mathrm{~mL}$ of aqueous $\mathrm{NaOH}$ solution prepared with $0.8 \mathrm{mg}$ of solid sodium hydroxide $(\mathrm{NaOH})$, to provide an alkaline environment, and the $\mathrm{pH}$ was adjusted to 11.0.The prepared extract solution was placed in a microwave reaction apparatus and heated at $75{ }^{\circ} \mathrm{C}$; the power of the device was $700 \mathrm{~W}$; $1.2 \mathrm{mmol}$ silver nitrate and $25 \%$ dilute aqueous ammonia were placed in a silver ammonia solution. Then a mixture of silver ammonia solution and $10 \mathrm{~mL}$ of $1 \%$ starch solution was prepared (the soluble starch is amylose and can act as a protective agent in the process of synthesizing silver nanoparticles). The mixture was injected into the lemongrass extract solution when the temperature of the extract solution reached the set temperature. The reaction was carried out for $3 \mathrm{~min}$. The color of the solution changed from yellow to pale brown. The nano-silver solution was prepared.

\section{Analytical Methods}

\section{$U V$-VIS characterization of silver nanoparticles}

Deionized water was measured in a UV-2100-type UV-VIS spectrophotometer (Unike (Shanghai) Instrument Co., Ltd., Shanghai, China) as a control. A sample of diluted nano-silver aqueous solution was placed in the sample cell for measurements.

\section{$X$-ray diffractometry (XRD)}

After centrifugation of the nano-silver solution at $10000 \mathrm{rpm}$, the obtained black powder was dried. The powder was tested in a D8 ADVANCE X-type X-ray diffractometer (Bruker, Karlsruhe, Germany) under the following conditions: copper target, incident wavelength of $0.15418 \mathrm{~nm}$, Ni filter, tube pressure of $40 \mathrm{KV}$, tube flow of $40 \mathrm{~mA}$, scan step size of $0.02^{\circ}$, scanning speed of $19.2 \mathrm{~s} / \mathrm{step}$, slit DS of $1^{\circ}$, and RS of $8 \mathrm{~mm}$ (corresponding to LynxExe array detector).

\section{Transmission electron microscopy (TEM)}

The dispersed nano-silver solution was dripped onto a copper mesh. The samples were dried for 1 min before observation under a Philips Tecnai10 transmission electron microscope (Amsterdam, Holland).

\section{Malvern nano-size and potential analyzer}

The Malvern nano-size and potential analyzer can determine the amount of different diameter particles in the solution by measuring the amount of light scattered at different angles in the solution in the case of incident light, whereby the particle size of the prepared nano-silver particles size has a rough judgment. After setting the test conditions in the software, the nano-silver solution was diluted several times and placed in the Malvern particle size tester for testing. 
Fourier transform infrared spectroscopy (FTIR)

The nanometer silver powder and the extract powder were mixed with potassium bromide powder. The mixture was ground and pressed into a sheet. The sample was placed in a Bruker TENSOR27 apparatus (Karlsruhe, Germany) for testing.

$X$-ray photoelectron spectrometry (XPS)

An AXIS Ultra DLD X-ray photoelectron spectrometer (Kratos Co., Manchester, Britain) was used. The chamber was operated at a vacuum of $\sim 5 \times 10^{-9}$ torr. The X-ray source was a monochromatic Al Kasource (Mono AlK $\alpha$ ) with and energy of $1487.7 \mathrm{eV}$ and $5 \mathrm{~mA} \times 15 \mathrm{kV}$, with a beam spot size of $700 \mu \mathrm{m} \times 300 \mu \mathrm{m}$. The scanning mode was CAE, with a full-spectrum scan of $170 \mathrm{eV}$ and narrow-band scan of $40 \mathrm{eV}$. The number of scans was 1 .

\section{RESULTS AND DISCUSSION}

\section{Characterization of Nano-silver Samples}

UV-VIS analysis

According to Mie scattering theory, the peak in Fig. 1 appeared at $416 \mathrm{~nm}$, which belongs to the band of the characteristic peak of ultraviolet spectroscopic spectrum of the spherical nano-silver particles (Ahmad et al. 2003). This symmetrical curve shows that the synthesized nano-silver particles had good dispersibility. After 30 days, there was no obvious agglomeration, indicating that the synthesized nano-silver particles were stable.

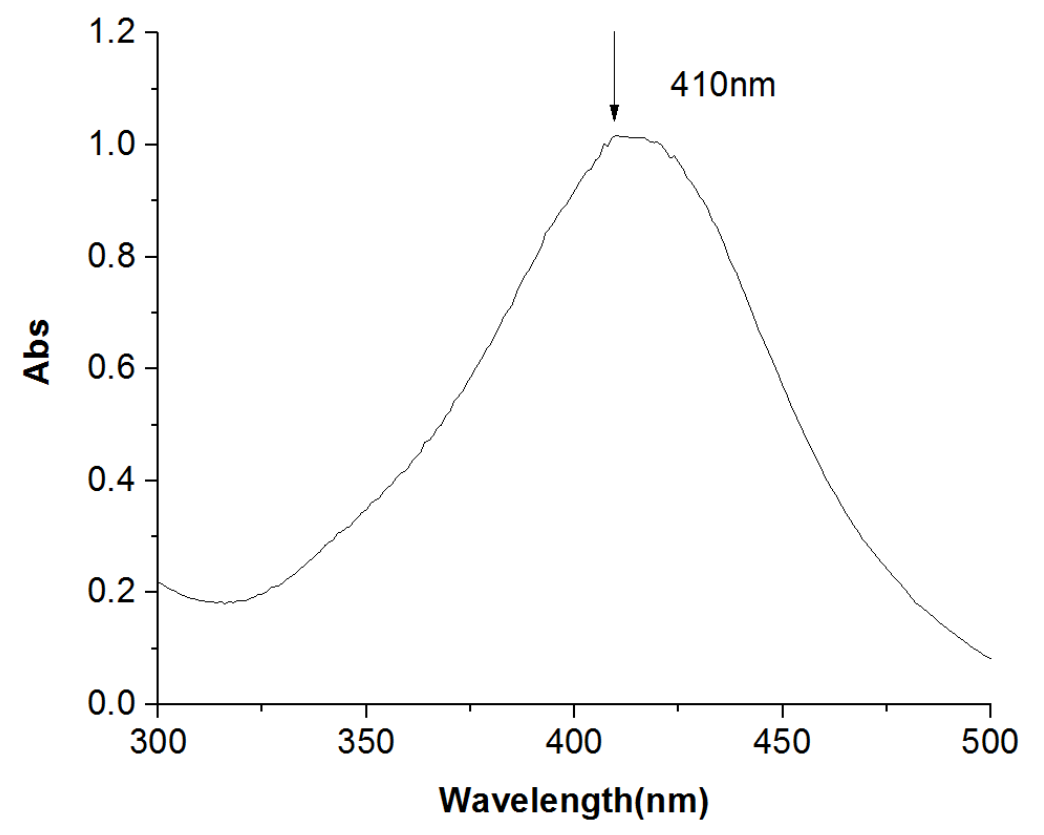

Fig. 1. Ultraviolet spectra of silver nanoparticles

\section{XRD analysis}

As shown in Fig. 2, the five principal peaks were $38.1^{\circ}, 44.2^{\circ}, 74.4^{\circ}, 77.4^{\circ}$, and $81.5^{\circ}$, which correspond to the five peak positions of the $\mathrm{Ag}$ spherical particles coinciding with elemental silver XRD pattern (JCPDS, NO 04-0783). These characteristic peaks correspond to $111 \mathrm{au}, 200 \mathrm{au}, 220 \mathrm{au}, 311 \mathrm{au}$, and $222 \mathrm{au}$, respectively, which shows that 
the nanoparticles prepared in this paper had the same face-centered cubic crystal structure as previously reported (Janardhanan et al. 2009). The width of the peak is related to the size of the nanoparticle (Prasad et al. 2006). It is further illustrated that the product obtained by this environmentally friendly method was pure crystal silver.

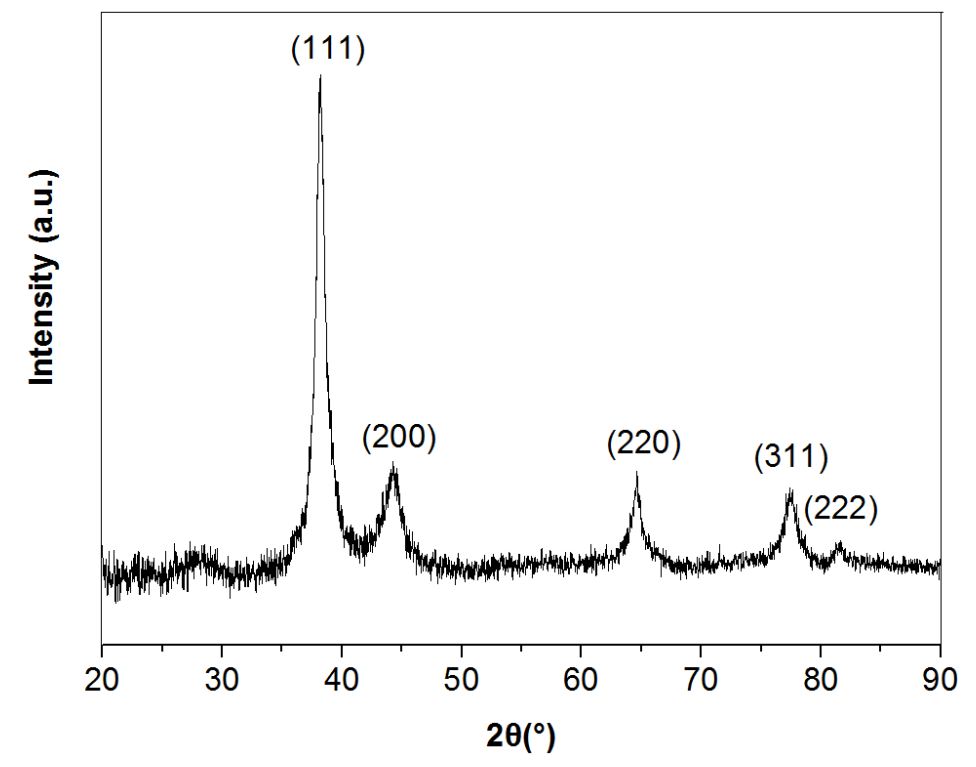

Fig. 2. X-ray diffraction pattern of silver nanoparticles

\section{TEM analysis}

Figure 3 shows the result of field emission transmission electron microscopy of the synthesized silver nanoparticles. The Fig. 3(a), (b), (c) and (d) shows the morphologies of the spherical nano-silver particles under $200 \mathrm{~nm}, 50 \mathrm{~nm}, 100 \mathrm{~nm}$, and $20 \mathrm{~nm}$ scale, respectively.

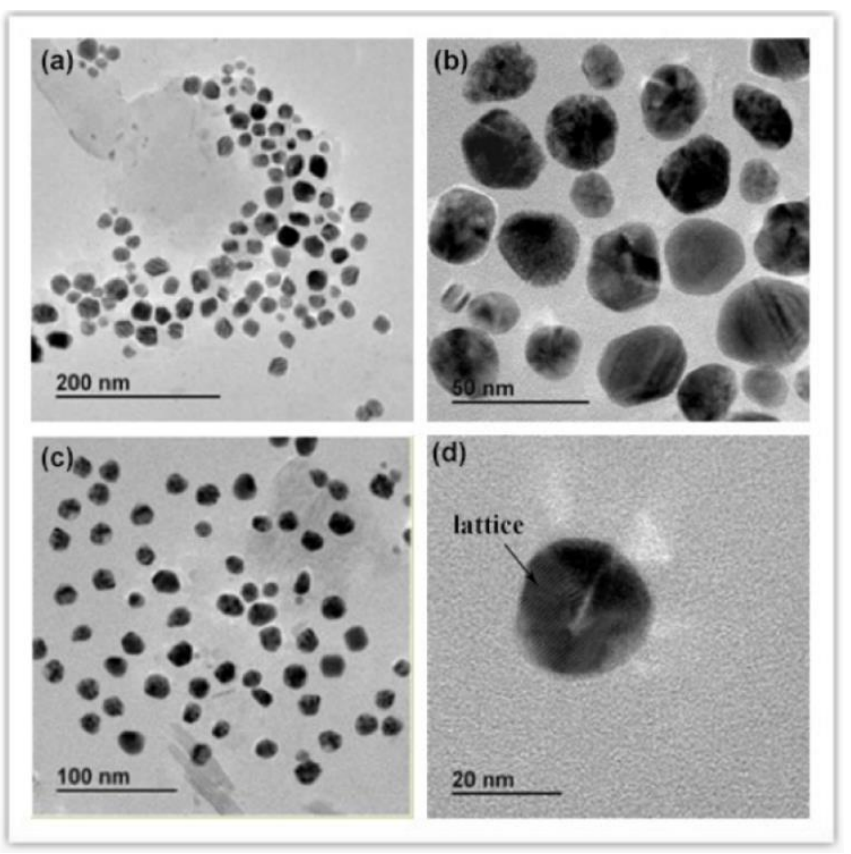

Fig. 3. Field emission transmission electron microscopy 
The reaction product consisted of spherical particles with a high crystallinity, and the average particle diameter was $25 \mathrm{~nm}$. The individual particles less than $10 \mathrm{~nm}$ had spherical shapes (Fig. 3), while the particles in the range from $20 \mathrm{~nm}$ to $30 \mathrm{~nm}$ were pentahedral or decahedral strictly, such that they could be called multiply twinned particles. The synthesized nano-silver particles were isotropic in shape and had a low aspect ratio. The results are consistent with the result of the symmetrical UV spectra obtained above, reflecting the monodispersity of the silver nanoparticles. Thus, the synthesized nano-silver particles had a high concentration and no agglomeration, indicating that the synthesized silver nanoparticles were stable and uniform in particle size distribution. Moreover, the particle size of the prepared silver nanoparticles was concentrated at 20 to $28 \mathrm{~nm}$, according to results from the Malvern nano-size and potential analyzer; the average size of uniform and stable spherical nanoparticles was $22.99 \mathrm{~nm}$.

\section{Malvern particle size analysis}

As shown in Fig. 4A, the prepared silver particles were concentrated in the distribution range of 20 to $28 \mathrm{~nm}$. There were some very small particles, but not a lot. There were almost no particles in the range of $40 \mathrm{~nm}$ or more, showing that the prepared nanosilver particles were relatively stable, and there was no apparent reunion of the larger particles. The calculated average particle size was $22.99 \pm 11.01 \mathrm{~nm}$.

In order to observe the stability of the nano silver solution prepared by the lemon grass extract, the sample was stored at room temperature $\left(25^{\circ} \mathrm{C}\right)$ for 90 days to observe whether it had a significant agglomeration. Part B of Fig. 4 shows colorless, deionized water on the left. The right side is the silver nanoparticles-ethanol dispersion after 3 months, which was brown with no obvious precipitation. The silver nanoparticles prepared by the method described in this paper were stable and difficult to agglomerate.

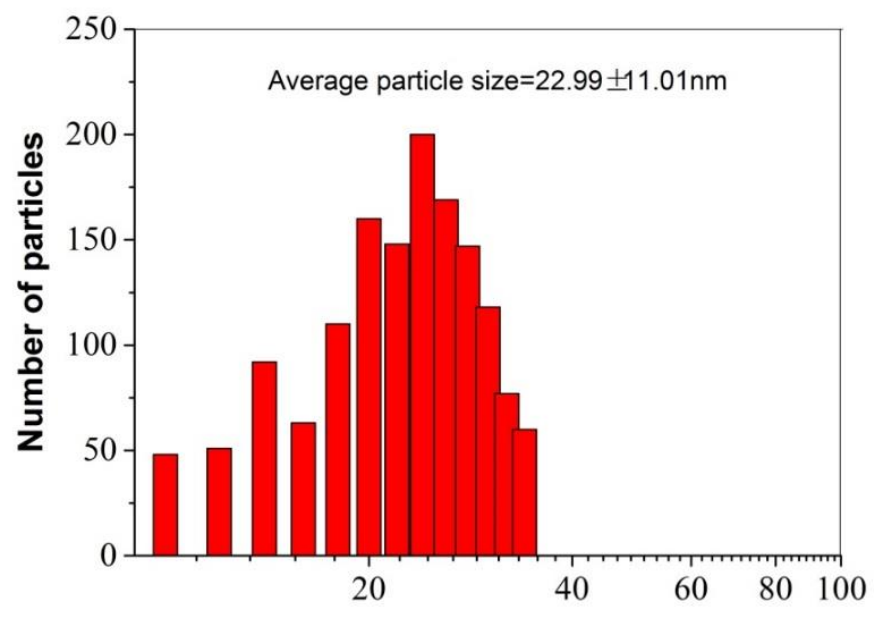

Particle size(nm)

A

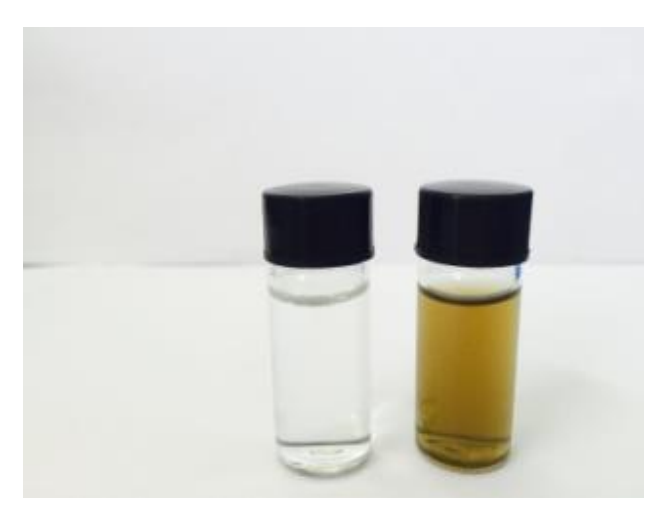

B

Fig. 4. A: Particle size distribution of spherical silver nanoparticles; B: The comparison deionized water and the silver nanoparticles-ethanol dispersion placed 3 months

\section{FTIR analysis}

The Fourier transform infrared spectra are shown in Fig. 5. Curve $a$ is the infrared spectrum of lemongrass extract. Curve $b$ is the spectrum of the mixed solution after the 
reaction. There was an absorption peak near $3000 \mathrm{~cm}^{-1}$ both in $a$ and $b$, which is the stretching vibration absorption of $\mathrm{C}-\mathrm{H}$ bond belonging to $-\mathrm{CH}_{2}-$ and $-\mathrm{CH}_{3}$. There was an absorption peak at $1577 \mathrm{~cm}^{-1}$ in curve $a$, which is attributable to the bending vibration of the N-H bond and it weakened in curve $b$. The absorption peak at $1395 \mathrm{~cm}^{-1}$ in curve $a$ is ascribed to the C-N stretching vibration. The absorption peak was shifted to $1371 \mathrm{~cm}^{-1}$ in the infrared spectra $b$, indicating that the amino group played an important role in the whole reduction process. The $\mathrm{C}-\mathrm{O}$ bond was obtained at $1156 \mathrm{~cm}^{-1}$ and the $\mathrm{C}=\mathrm{O}$ bond was 1648 $\mathrm{cm}^{-1}$ in $b$, indicating that carboxylate ions were present in the reaction product. Carboxylate ions and silver ions may also occur in $\mathrm{Ag}-\mathrm{O}$ chemical bonding reactions. There was a strong absorption peak near $1028 \mathrm{~cm}^{-1}$ in curve $a$, which belongs to the vibration absorption of $-\mathrm{OH}$ in the primary alcohol, which indicates that the soluble starch macromolecules may have been coated on the surface of nano-silver particles and were acting as a protective agent.

Through the infrared analysis of the lemongrass extract, it can be concluded that most of the lemongrass extract is amide compounds, which may be derived from the macromolecules such as proteins and peptides in plant cells. The amino group were hydrolyzed in alkaline environment under heating conditions: $\mathrm{RCONH}_{2}+\mathrm{OH} \rightarrow$ (heating) $-\mathrm{RCOO}-+\mathrm{NH}_{3} \uparrow$.

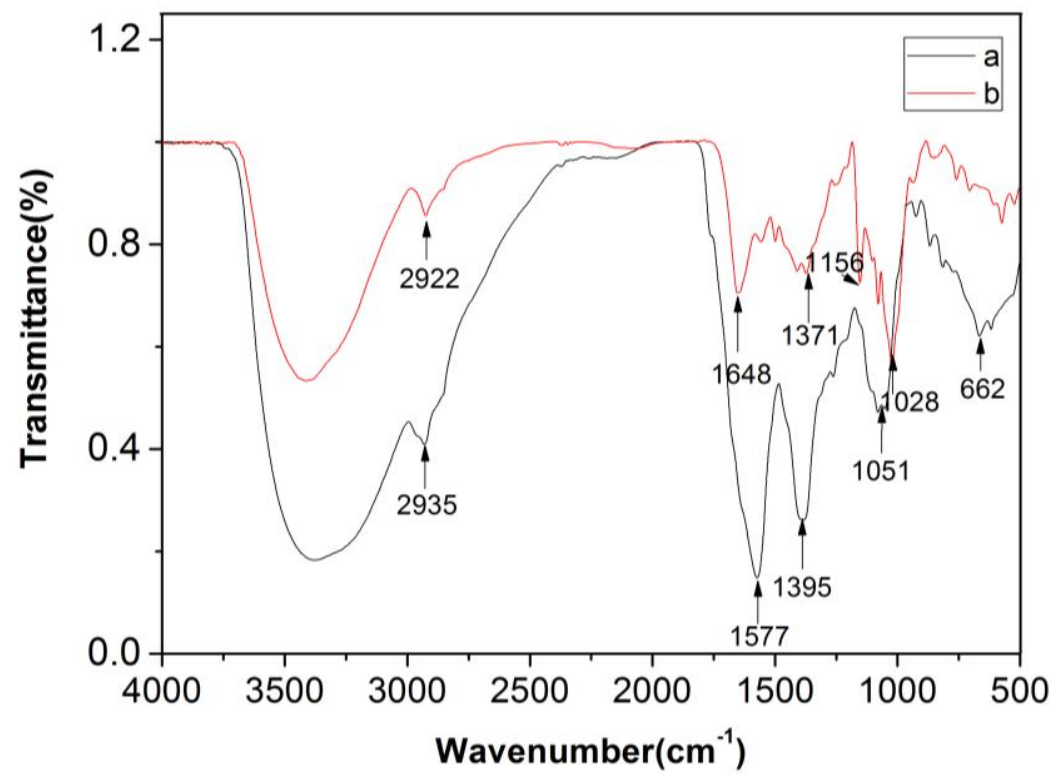

Fig. 5. Infrared spectra of lemongrass extract and reaction products

\section{XPS analysis}

As shown in Fig 6, the reduction reaction products were mainly constituted by the three elements carbon, oxygen, and silver. The XPS peak software was employed to divide the resulting spectrum into the peaks. Figure 7 shows the binding energies of two obvious peak positions of silver nanoparticles are $374.27 \mathrm{eV}$ and $368.20 \mathrm{eV}$, corresponding to $3 \mathrm{~d}_{3 / 2}$ and $3 \mathrm{~d}_{5 / 2}$ binding energy. These positions are as same as the positions of the standard $\mathrm{Ag}$, indicating that the prepared nano-silver existed in the form of crystals. The binding energy of peak 1 was $368.60 \mathrm{eV}$, which belonged to the $3 \mathrm{~d}_{5 / 2}$ binding energy of the silver element. 
This result indicates that this part of the silver element came from the silver-containing conjugates, confirming that some silver nanoparticles were bound with a protective agent and an active substance from the reaction system. Peak 2 corresponds to the silver element $3 \mathrm{~d}_{5 / 2}$ binding energy of $368.04 \mathrm{eV}$, indicating that part of the silver element was constituted as AgO. There may be a small part of the silver by air oxidation in the high-temperature reaction process. Peak 3 corresponds to the $3 \mathrm{~d}_{3 / 2}$ binding energy of the silver element, which indicates that most of the synthesized material was elemental silver.

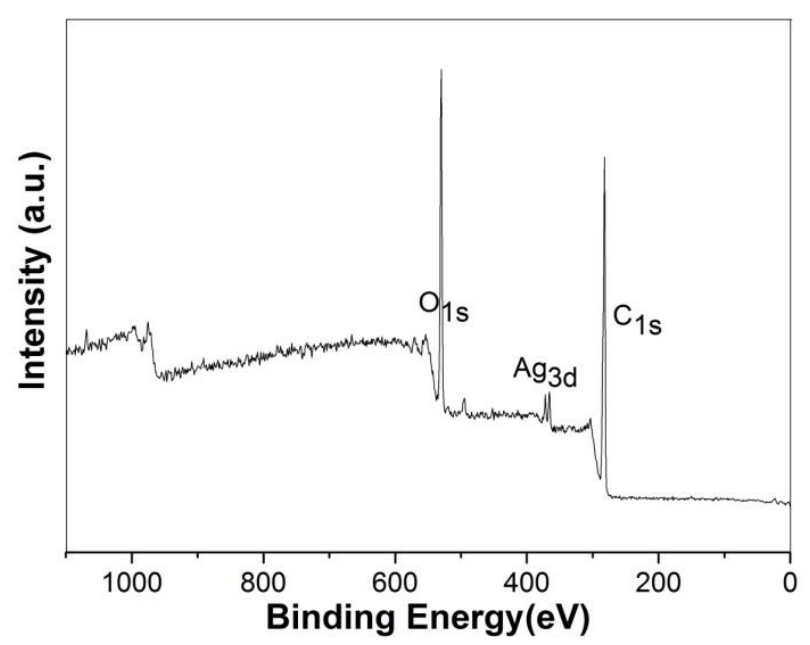

Fig. 6. X-ray photoelectron spectroscopy of silver nanoparticles

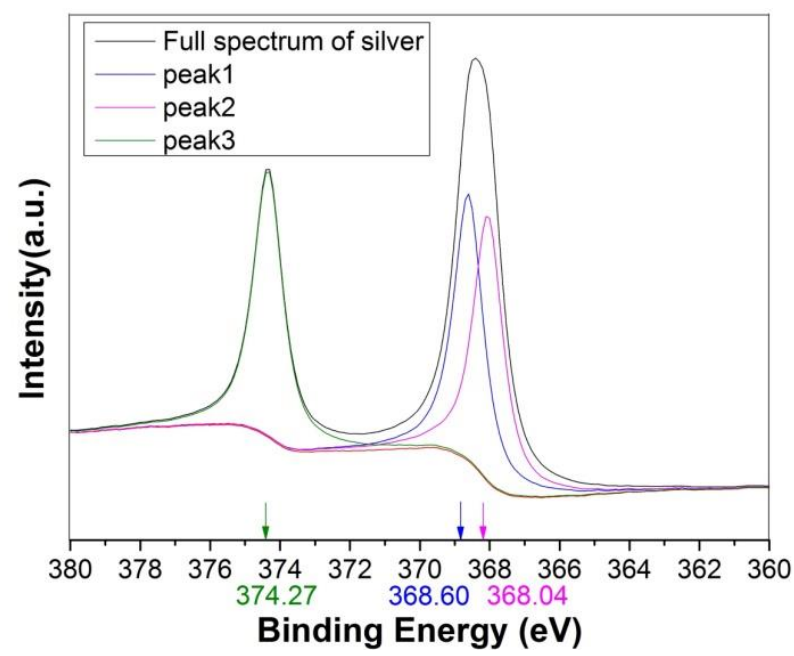

Fig. 7. XPS silver spectrum of reaction product

\section{CONCLUSIONS}

1. The spherical nano-silver particles were prepared using ethanol extracts of lemongrass and silver nitrate by microwave heating. This approach is time-saving, low in energy and resource costs, and environmentally friendly. 
2. Through the analysis of XPS and infrared spectra, it was presumed that the amide compounds in the plant extracts played a role as reductant during the course of the reaction.

3. The particle size of the prepared silver nanoparticles was concentrated at 20 to $28 \mathrm{~nm}$, and the average size of uniform and stable spherical nanoparticles was $22.99 \mathrm{~nm}$. It is worthwhile to study whether preparation of nano-silver by lemongrass extract can be put into industrial production in large quantities.

\section{ACKNOWLEDGMENTS}

This research was financially supported by the independent research project of Key Laboratory of Pulp and Paper, South China University of Technology (Nos. 2016C02 and 2016C01), the Science and Technology Project of Guangdong Province (Nos. 2013B010401007 and 201607020045), the Fundamental Research Funds for the Central Universities (Nos. D2154620), and the Development Fund of Key Laboratory of Pulp and Paper Science and Technology of Ministry of Education of China, Qilu University of Technology (No. KF201502).

\section{REFERENCES CITED}

Ahmad, A., Mukherjee, P., Senapati, S., Mandal, D., Khan, M. I., Kumar, R., and Sastryc, M. (2003). "Extracellular biosynthesis of silver nanoparticles using the fungus Fusarium oxysporum," Colloids and Surfaces B: Biointerfaces 28(4), 313318. DOI: 10.1016/S0927-7765(02)00174-1

Ajayi, E., and Afolayan, A. (2017). "Green synthesis, characterization and biological activities of silver nanoparticles from alkalinized Cymbopogon citratus Stapf," Advances in Natural Sciences-Nanoscience and Nanotechnology 8(1), 015-017. DOI: 10.1088/2043-6254/aa5cf7

Ball, P., and Garwin, L. (1992). "Science at the atomic scale," Nature 355(6363), 761766. DOI: $10.1038 / 355761 \mathrm{a} 0$

Biswal, J., Ramnani, S. P., Shirolikar, S., and Sabharwal, S. (2009). "Synthesis of guargum-stabilized nanosized silver clusters with $\gamma$ radiation," Journal of Applied Polymer Science 114(4), 2348-2355. DOI: 10.1002/app.30113

Chandran, S. P., Chaudhary, M., Pasricha, R., Ahmad, A., and Sastry, M. (2006). "Synthesis of gold nanotriangles and silver nanoparticles using Aloe vera plant extract," American Chemical Society and American Institute of Chemical Engineers 22(2), 577-83. DOI: 10.1021/bp0501423

Chang, J. Y., Chang, J. J., Lo, B., Tzing, S. H., and Ling, Y. C. (2003). "Silver nanoparticles spontaneous organize into nanowires and nanobanners in supercritical water," Chem. Phys. Lett. 379 (3-4), 261-267. DOI: 10.1016/j.cplett.2003.08.047

Chou, K. S. and Ren, C. Y. (2000). "Synthesis of nanosized silver particles by chemical reduction method," Materials Chemistry and Physics 64(3), 241-246. DOI: 10.1016/S0254-0584(00)00223-6

Dan, E. (2009). Biosynthesis of Silver Nanoparticles by Sundried Aleurites moluccana Leaf and Yeast Pichia pastoris, Master's Thesis, Xiamen University, Xiamen, China. 
Geetha, N., Harini, K., Showmya, J. J., and Priya, K. S. (2012). "Biofabrication of silver nanoparticles using leaf extract of Chromolaena odorata (L.) King and Robinson," Intl. Conf. on Nuclear Energy, Environ. and Biological Sciences, Bangkok, Thailand.

Hirano, S., Wakasa, Y., Saka, A., Yoshizawa, S., Oya-Seimiya, Y., Hishinuma, Y., Nishimura, A., Matsumoto, A., and Kumakura, H. (2003). "Preparation of Bi-2223 bulk composed with silver-alloy wire," Physica C: Superconductivity 392-396(1), 458-462. DOI: 10.1016/S0921-4534(03)01222-X

Janardhanan, R., Karuppaiah, M., Hebalkar, N., and Rao, T. N. (2009). "Synthesis and surface chemistry of nano silver particles," Polyhedron 28(12), 2522-2530.

DOI:10.1016/j.poly.2009.05.038

Khanna, P. K., Singha, N., Charan, S., and Viswanath, A. K. (2005a). "Synthesis of Ag /polyaniline nanocomposite via an in situ photo-redox mechanism," Materials Chemistry and Physics 92(1), 214-219. DOI: 10.1016/j.matchemphys.2005.01.011

Khanna, P.K., Singh, N., Charan, S., Subbarao, V. V. V. S., Gokhale, R., and Mulik, U. P. (2005b). "Synthesis and characterization of Ag/PVA nanocomposite by chemical reduction method," Mater. Chem. Phys. 93(1), 117-121. DOI: 10.1016/j.matchemphys.2005.02.029

Korchagina, A. I., Kuksanova, N. K., Lavrukhin, A. V., Fadeev, S. N., Salimov, R. A., Bardakhanov, S. P., Goncharov, V. B., Suknev, A. P., Paukshtis, E. A., Larina, T. V., Zaikovskii, V. I., Bogdanov, S. V., and Bal'zhinimaev, B. S. (2005). "Production of silver nano-powders by electron beam evaporation," Vacuum 77(4), 485-491. DOI: 10.1016/j.vacuum.2004.09.015

Lee, H. J., Yeo, S. Y., and Jeong, S. H. (2003). "Antibacterial effect of nanosized silver colloidal solution on textile fabrics," Journal of Materials Science 38(10), 2199-2204. DOI: 10.1023/A:1023736416361

Lin, J. C., and Wang, C. Y. (1996). "Effects of surfactant treatment of silver powder on the rheology of its thick-film paste," Materials Chemistry and Physics 45(2), 136144. DOI: 10.1016/0254-0584(96)80091-5

Manish, D., Seema, B., and Kushwah, B. S. (2009). "Green synthesis of nanosilver particles from extract of Eucalyptus hybrid (Safeda) leaf," Nanomaterials and Biostructures 4(3), 537-543.

Naik, R. R., Stringer, S. J., Agarwal, G., Jones, S. E., and Stone, M. O. (2002). "Biomimetic synthesis and patterning of silver nanoparticles," Nat. Mater. 1(3), 169172. DOI: $10.1038 /$ nmat 758

Park, K., Seo, D., and Lee, J. (2008). "Conductivity of silver paste prepared from nanoparticles," Colloids and Surfaces A: Physicochemical and Engineering Aspects 313-314(SI), 351-354. DOI:10.1016/j.colsurfa.2007.04.147

Pastoriza-Santos, I., and Liz-Marzán, L. M. (2002). "Synthesis of silver nanoprisms in DMF," Nano Letters 2(8), 903-905. DOI: 10.1021/n1025638i

Prasad, V., Souza, C. D., Yadav, D., Shaikh, A. J., and Vigneshwaran, N. (2006). "Spectroscopic characterization of zinc oxide nanorods synthesized by solid-state reaction," Spectrochimica Acta Part A: Molecular and Biomolecular Spectroscopy 65(1), 173-78. DOI: 10.1016/j.saa.2005.10.001

Rodríguez-Sánchez, L., Blanco, M. C., and López-Quintela, M. A. (2000). "Electrochemical synthesis of silver nanoparticles," J. Phys. Chem. B 104(41): 96839688. DOI: 10.1021/jp001761r

Ryu, B.H., Choi, Y., Park, H.S., Byun, J.H., Kong, K., Lee, J.O., and Chang, H. (2005). "Synthesis of highly concentrated silver nanosol and its application to inkjet 
printing," Colloids Surf. A: Physicochem. Eng. Aspects 270-271, 345-351. DOI:

10.1016/j.colsurfa.2005.09.005

Shaik, F., Zhang, W. Q., and Niu, W. X. (2017). "A generalized method for the synthesis of ligand-free $\mathrm{M} @ \mathrm{SiO}_{2}(\mathrm{M}=\mathrm{Ag}, \mathrm{Au}, \mathrm{Pd}, \mathrm{Pt})$ yolk-shell nanoparticles," The ACS Journal of Surfaces and Colloids 33(13), 3281-3286. DOI: 10.1021/acs.langmuir.7b00141

Shalaka, A. M., Pratik R. C., Vrishali B. S., Suresh P.K. (2011). "Rapid biosynthesis of silver nanoparticles using Cymbopogon citratus (Lemongrass) and its antimicrobial activity," Nano-Micro Lett. 3(3), 189-194. DOI: 10.3786/nml.v3i3.p189-194

Song, J. Y., and Kim, B. S. (2009). "Rapid biological synthesis of silver nanoparticles using plant leaf extracts," Bioprocess and Biosystems Engineering 32(1), 79-84. DOI: 10.1007/s00449-008-0224-6

Sun, Y. G., and Xia, Y. N. (2002). "Shape-controlled synthesis of gold and silver nanoparticles," Science 298(5601), 2176-2179. DOI: 10.1126/science.1077229

Tian, X. L., Wang, W. H., and Cao, G. Y. (2007). "A facile aqueous-phase route for the synthesis of silver nanoplates," Mater. Lett. 61(1),130-133. DOI: 10.1016/j.matlet.2006.04.021

Tsuji, T., Kakita, T., and Tsuji, M. (2003). "Preparation of nano-size particles of silver with femtosecond laser ablation in water," Applied Surface Science 206(1-4), 314320. DOI: 10.1016/S0169-4332(02)01230-8

Wang, T., Chen, X., and Lu, G. Q. (2007). "Low-temperature sintering with nano-silver paste in die-attached interconnection," Journal of Electronic Materials 36(10), 1333 1340. DOI: $10.1007 / \mathrm{s} 11664-007-0230-5$

Xie, Y. W., Ye, R. Q., and Liu, H. L. (2006). "Synthesis of silver nanoparticles in reverse micelles stabilized by natural biosurfactant," Colloids and Surfaces A: Physicochem. and Eng. Aspects 279(1-3), 175-178. DOI: 10.1016/j.colsurfa.2005.12.056

Xiong, Y. Q., Wu, H., Guo, Y., Sun, Y., Yang, D. Q., and Da, D. A. (2000). "Preparation and characterization of nanostructured silver thin films deposited by radio frequency magnetron sputtering," Thin Solid Films 375 (1-2), 300-303. DOI: 10.1016/S00406090(00)01253-0.

Yin, B. S., Ma, H. Y., Wang, S. Y., and Chen, S. H. (2003). "Electrochemical synthesis of silver nanoparticles under protection of poly (N-vinylpyrrolidone)," J. Phys. Chem. B 107(34), 8898-8904. DOI: 10.1021/jp0349031

Zhang, W. Z., Qiao, X. L., Chen, J. G., and Wang, H. S. (2006). "Preparation of silver nanoparticles in water-in-oil AOT reverse micelles," Journal of Colloid and Interface Science 302(1), 37-373. DOI: 10.1016/j.jcis.2006.06.035

Zhang, Z. T., Zhao, B., and Hu, L. M. (1996). "PVP protective mechanism of ultrafine silver powder synthesized by chemical reduction processes," Journal of Solid State Chemistry 121(1), 105-110. DOI: 10.1006/jssc.1996.0015

Zhou, M., Chen, S. H., Zhao, S. Y., and Ma, H. Y. (2006). "One-step synthesis of Au-Ag alloy nanoparticles by a convenient electrochemical method,"Physica E: Lowdimensional Systems and Nanostructures 33(1), 28-34. DOI: 10.1016/j.physe.2005.10.012

Article submitted: May 5, 2017; Peer review completed: July 22, 2017; Revised version received and accepted: August 5, 2017; Published: August 14, 2017.

DOI: 10.15376/biores.12.4.7096-7106 